\title{
Modelling of the operation of a refrigeration unit using radiative cooling to maintain the storage temperature in the cold room
}

\author{
Alexandr P. Tsoy ${ }^{(\mathrm{a})}$, Alexandr S. Granovsky ${ }^{(\mathrm{a})}$, \\ Diana $A$. Tsoy ${ }^{(b)}$ \\ (a) Almaty Technological University \\ Almaty, A05H0E2, Kazakhstan, teniz@bk.ru \\ (b) ITMO University \\ Saint-Petersburg, 197101, Russian Federation, ditsoy@gmail.com
}

\begin{abstract}
The results of the research, which show the effect of radiative cooling on the temperature of food storage chamber during the cold season in the cities of Almaty and Kostanay (Kazakhstan) were obtained through computer simulation of the operation cycle. In the installation modelled, pumping circulation of a heat carrier cooled at night in radiators is used. The radiators of the installation cover the entire roof of the cold room $\left(12 \mathrm{~m}^{2}\right)$. Computer simulation shows that the required temperature in the cooled chamber $\left(0 \ldots+3^{\circ} \mathrm{C}\right)$ is maintained in Almaty for $8.5 \%$, and in Kostanay for $28.2 \%$ of the total length of the year. The average coefficient of performance of the unit was 3.43 in Almaty and 4.63 in Kostanay. Although the installation with radiation cooling is operational, in the proposed scenario its practical application is not advisable.
\end{abstract}

Keywords: radiative cooling, effective radiation, natural cooling

\section{INTRODUCTION}

Radiative cooling (hereinafter referred to as RC) - is a method of producing cold, based on the release of heat in the form of infrared radiation through the Earth's atmosphere into the surrounding space (Zhao, Xu et al., 2019; Ahmad et al., 2019; Vall and Castell, 2017; Hossain et al., 2016). It was previously suggested that in a sharply continental climate with cold winters, RC can be used to maintain the temperature of the cooled object around $0^{\circ} \mathrm{C}$ and lower (Tsoy et al., 2017; Tsoy et al., 2015), while most of the research is currently underway on the use of RC in summer air conditioning systems (Zhao, Lu et al., 2019; Aili et al., 2019; Joubert and Dobson, 2017; Liu et al., 2017; Tevar and et al., 2015; Zhang and Niu, 2012). At the same time, it can be assumed that the use of combined RC systems together with vapor compression refrigeration machines will reduce energy consumption and may also lead to a reduction in the use of ozone-depleting substances and greenhouse gases, which are currently limited in use (Bolaji and Huan, 2013; Tassou and Ge, 2008 ). Only a small number of studies have been carried out to study the possibilities 
of using RC in winter in the northern regions of the planet (Karagusov, Goshlya et al., 2018; Karagusov, Serdyuk et al., 2018). In addition, at the moment there are no studies detailing the operation of the RC system during the annual cycle under these conditions. In this regard, the aim of this work is to study the operation of the installation using RC to maintain a constant temperature inside the cold room during the annual cycle in a sharply continental climate.

\section{RESEARCH METHODS AND RESULTS}

\subsection{Simulated installation}

Previously, by the research group a computer model for the study of RC systems (Tsoy et al., 2019) was developed. In current research, this model was used to study the process of maintaining the temperature in the cold room using the radiation-cooled unit shown in Fig.1.

At any time when it is possible to cool the coolant in the radiator and there is no risk of solidification, the pump P1 is turned on and delivers the coolant to the radiators R1 ... R6. After that, the cooled coolant is returned to the cold accumulator A. When the temperature in the refrigerator is higher than the set temperature, the pump P2 and the air cooler fan M3 are turned on. The coolant is pumped from the cold accumulator to the air cooler, where it collects heat from the cooled air until the temperature in the cold room drops to the setting value. Further, the pump will turn on only when the temperature in the chamber rises by the differential value.

The cooled object is a cold room with internal dimensions of 3 by $4 \mathrm{~m}$ and a height of $3 \mathrm{~m}$. The fencing of the cold room is made of mineral wool $0.15 \mathrm{~m}$ thick. When calculating heat gain through fencing, we neglect the influence of solar radiation in the daytime on the amount of heat gain, as well as heat inertia of enclosing structures and stored products. 


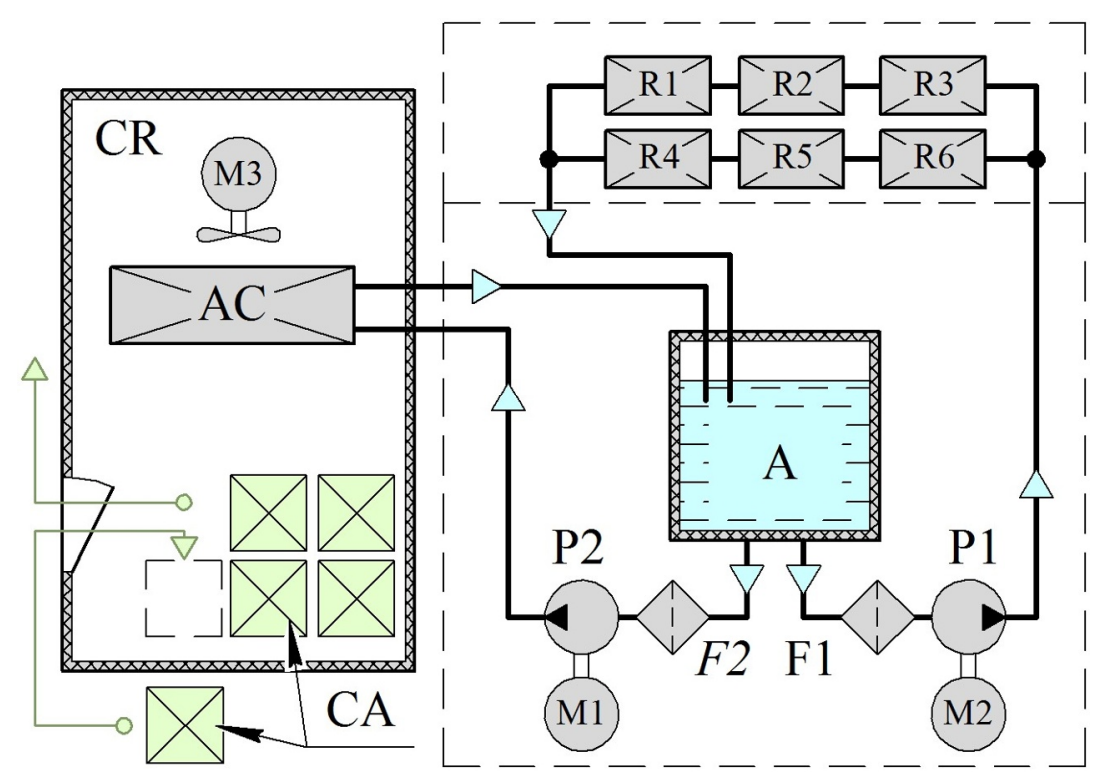

Figure 1. Schematic diagram of a simulated installation with radiation cooling:

$\mathrm{A}$ - cold accumulator; $\mathrm{AC}$ - air cooler; $\mathrm{CA}$ - refrigerated products; $\mathrm{CR}$ refrigerated room; F1, F2 - filters; M1, M2 - electric motors of pumps; M3 - air cooler fan motor; P1, P2 - pumps; R1 ... R6 - radiators

The cold room is used to store food products for which the storage temperature is in the range from 0 to $+3^{\circ} \mathrm{C}$. The proposed scenario is developed with the operational heat inflows which are typical of conventional cold rooms for food products. On average, they have the following values per day: heat gain from ventilation with a factor of 2 chamber volumes per day $(45 \mathrm{~W})$, heat gain from opening doors $(260 \mathrm{~W})$, heat gain from refrigeration processing of the product based on updating $10 \%$ of the cargo weight every day $(300 \mathrm{~W})$, heat gain from one person staying in the chamber $(70 \mathrm{~W})$, heat gain from lighting $(15 \mathrm{~W})$ and from air cooler fans $(98 \mathrm{~W})$. Considering the above factors, operational heat inflows were assumed constant and have a value of $788 \mathrm{~W}$ (or $65.6 \mathrm{~W} / \mathrm{m}^{2}$ of the refrigerated room).

Radiators R1 ... R6 cover the entire roof of the cold room and have a total radiating surface area of $12 \mathrm{~m}^{2}$. Radiators have the shape of a Z-shaped collector (Karvounis et al., 2019) with a radiating surface attached to them, do not have a selective coating and can only cool the coolant at night, as was done in (Tsoy et al., 2019) . The effect of precipitation on the radiator is neglected. Calculation of the amount of heat discharged in the form of radiation by the radiator is carried out according to a simplified method from (Samuel et al., 2013).

A finned tube heat exchanger with wound fins and a total heat exchange surface area of $7 \mathrm{~m}^{2}$ is used as an air cooler. The power of the electric motors of the air cooler fans is 98 watts.

An aqueous solution of propylene glycol with a mass concentration of $50 \%$ and a freezing pointof $-33^{\circ} \mathrm{C}$ is charged as a coolant in the hydraulic circuit to 
eliminate the risk of it freezing in the winter. The thermophysical properties of the coolant are calculated according to data from (Bell et al., 2014).

The cold accumulator is a cubic capacity into which $1000 \mathrm{~kg}$ of coolant is charged, coated with thermal insulation made of mineral wool $0.025 \mathrm{~m}$ thick. It is located inside the building. The mass flow rate of the coolant created by each of the pumps during the simulation is considered constant and is $0.12 \mathrm{~kg} / \mathrm{s}$.

\subsection{Climate data used}

In the simulation, data from weather stations in the cities of Almaty and Kostanay for 2018 were used (Riliable prognosis Rp5, 2019). The weather data for 2018 in the city of Almaty is presented in Fig. 2, and about the weather in the city of Kostanay - in Fig. 3

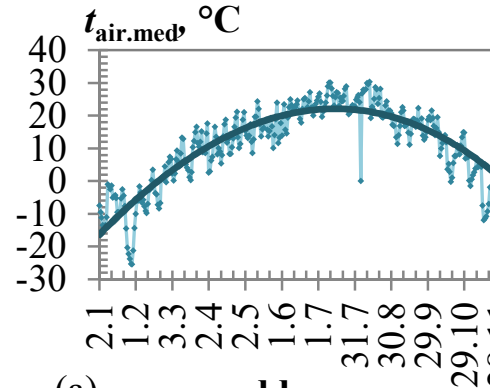

(a) $\tau$, dd.mm

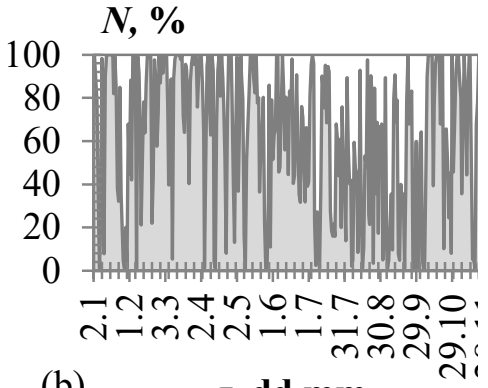

(b)

$\tau$, dd.mm

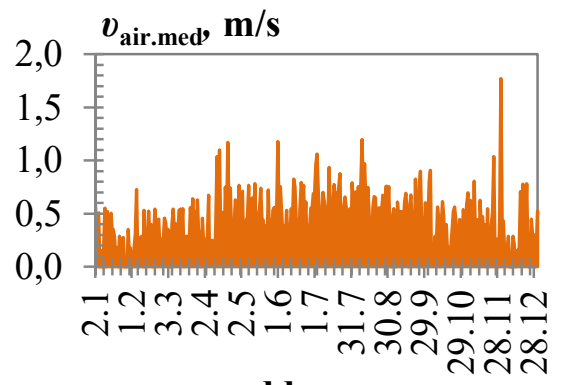

(c)

$\tau$, dd.mm

Figure 2. Climate data in the city of Almaty for 2018:

$\mathrm{a}$ - the average daily temperature; $\mathrm{b}$ - total cloud cover; $\mathrm{c}$ - the average daily value of wind speed 

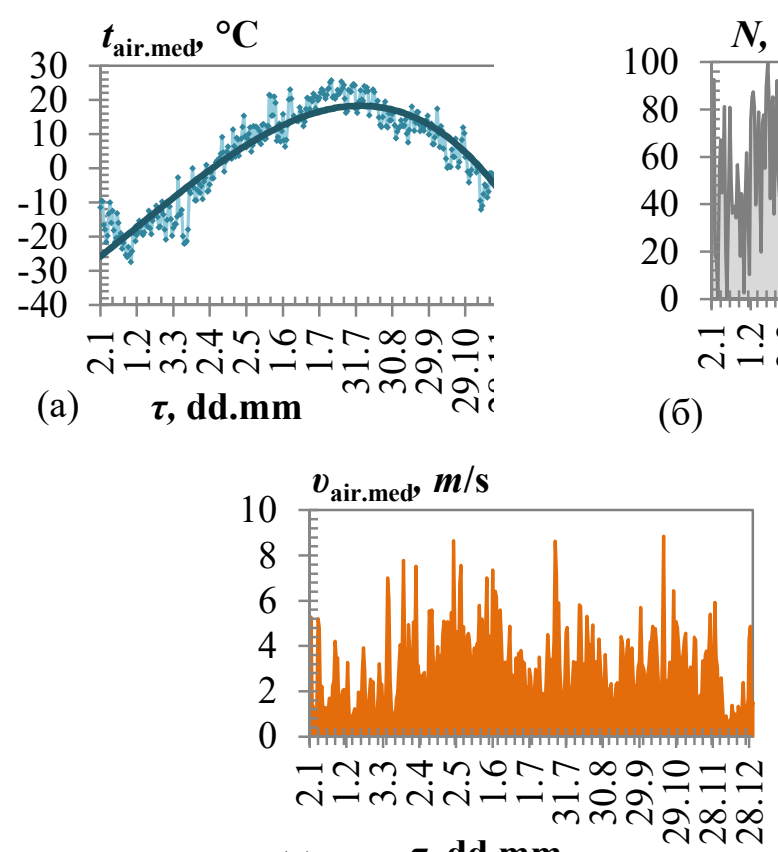

(в)

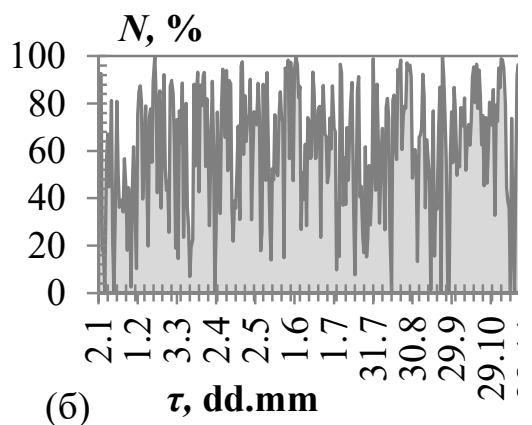

(б)

Figure 3. Climate data in the city of Kostanay for 2018:

$\mathrm{a}$ - the average daily temperature; $\mathrm{b}$ - total cloud cover; $\mathrm{c}$ - the average daily value of wind speed

\subsection{Simulation results per day}

To begin with, in order to verify the correctness of the computational algorithm, we consider in detail the result of modeling the operation of the installation for a three-day period from January 3 to 5, 2018 in the conditions of the city of Almaty (Fig. 4). Coolant cooling in the cold accumulator (curve 3 ) is observed at night from 18:00 to 09:00.

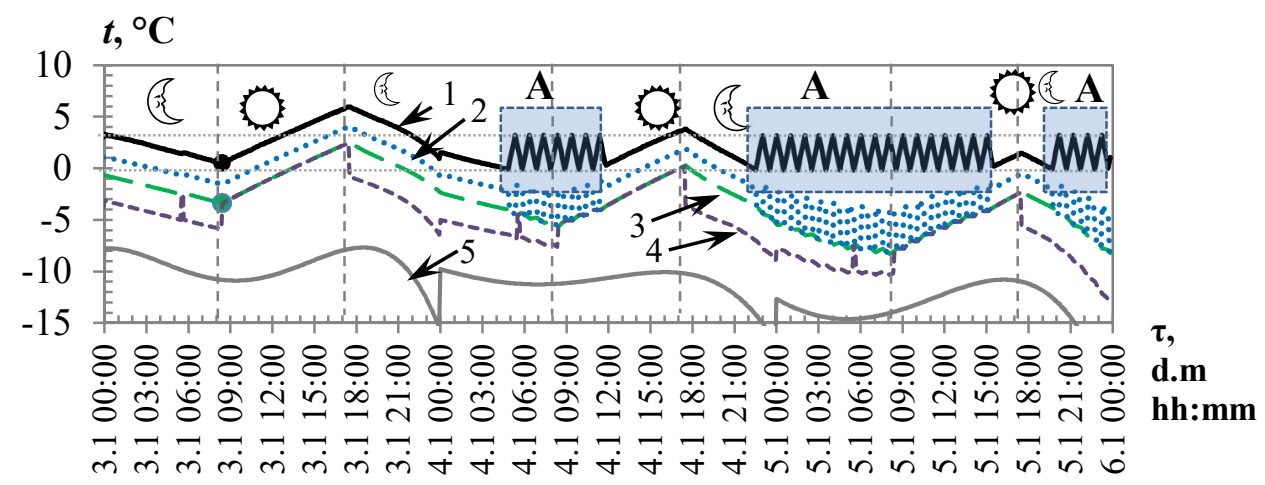

Figure 4. Temperature changes in a radiation-cooled installation from January 3 to 5, 2018: 
1 - average temperature in the cold room; 2 - temperature of the coolant at the outlet of the air cooler;

3 - temperature of the coolant in the cold accumulator; 4 - temperature of the coolant at the outlet of the radiator; 5 - air temperature

Cooling occurs due to the operation of radiators, as well as due to heat loss through the enclosing structures of the cold room. The temperature of the coolant at the outlet of the radiators (curve 4 ) is $2.5 \mathrm{~K}$ lower than the temperature of the coolant in the cold accumulator (curve 3). In the daytime, the radiators are turned off. This stops the coolant. As a result, the temperature in the cold accumulator rises between 9:00 and 18:00.

Almost all the time, the circulation pump delivers the coolant to the air cooler. When passing through the air cooler (curve 2), the coolant is heated by about $2 \mathrm{~K}$ due to the heat from the air in the cooled volume.

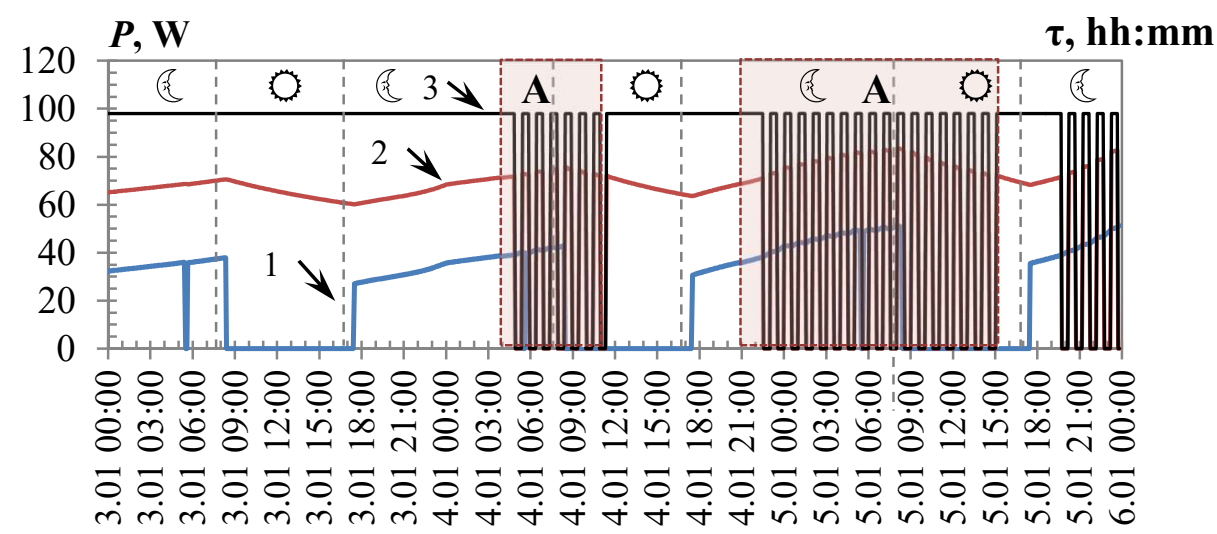

Figure 5. Change in energy consumption of pumps:

1 - power consumption of the pump P1 (supplying coolant to the radiators);

2 - power consumption of the pump P2 (supplying coolant to the air cooler);

3 - power consumption of air cooler fans

When the air temperature drops to $0^{\circ} \mathrm{C}$ in the cold room, the circulation pump and air cooler fans operate cyclically (see areas A).

The result of the calculation of energy consumption by system elements in the period under consideration is presented in Fig. 5. Pump 2 consumes more energy than pump 1 due to the high pressure loss (about 1 Bar) in a standard air cooler.

\subsection{Modeling results for the year}

Next, the cycle of installation work was simulated in the climate of the cities of Almaty and Kostanay for 2018 to maintain the temperature in the refrigerator in the spring and autumn periods of the year. Modeling from April to September was not carried out due to the fact that the installation could not reach the required temperature in a given period of time. 
As can be seen from Fig. 6a and 7a, the required air temperature in the refrigerator $\left(0 \ldots+3{ }^{\circ} \mathrm{C}\right)$ in the city of Almaty was observed only in four months: January, February, November and December. The rest of the year, the temperature in the refrigerator was above $+10^{\circ} \mathrm{C}$. In the city of Kostanay (Fig. $6 \mathrm{~b}$ and $7 \mathrm{~b}$ ), the required temperature values were observed for five months: in January, February, March, November and December.
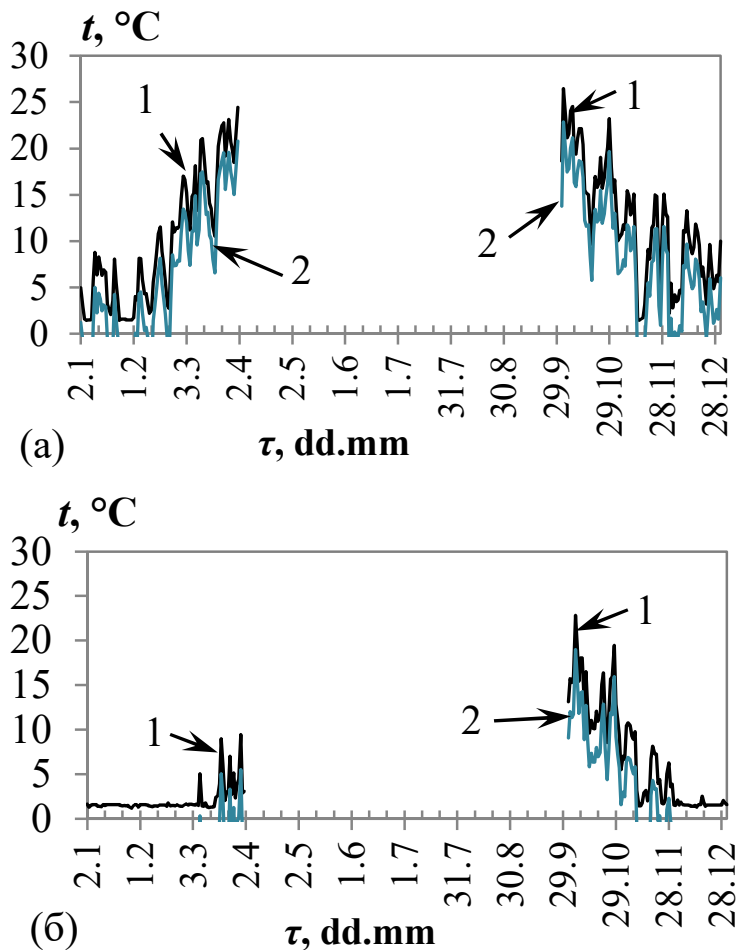

Figure 6. Temperatures in the refrigerator during the year:

1 - daily average temperature inside the refrigerator; 2 - daily average temperature in the cold accumulator;

$\mathrm{a}$ - in the city of Almaty; $\mathrm{b}$ - in the city of Kostanay

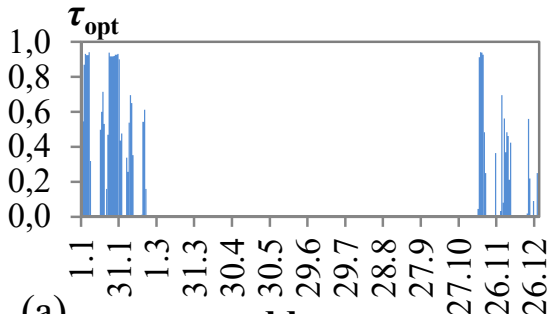

(a) $\tau$, dd.mm

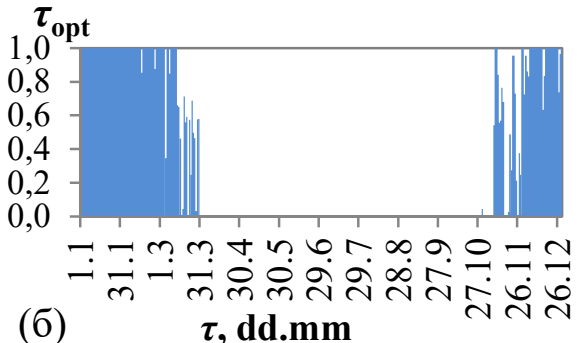

(б)

\section{$\tau$, dd.mm}

Figure 7. Change during the year of the part of the total length of the day when the air temperature inside the cold room was in the required range

( 1 - in the city of Almaty; 2 - in the city of Kostanay) 


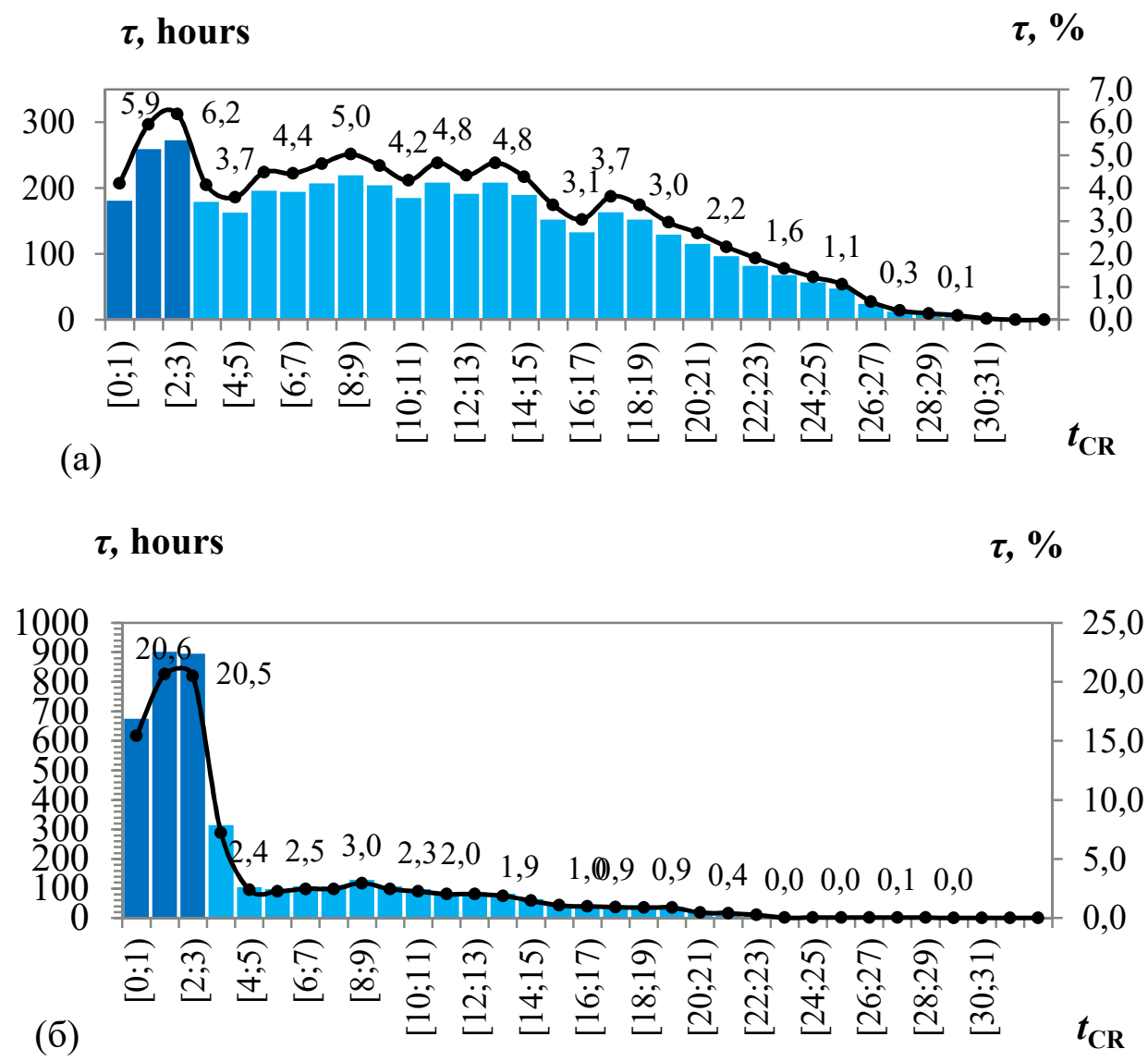

Figure 8. The total time for the considered period when the temperature in the refrigerator is in the specified range: $a$-in the city of Almaty; $b$ - in the city of

Kostanay

Next, we calculate the length of time when the air temperature inside the cold room was in a certain range (Fig. 8). The figure on the auxiliary axis on the right shows the percentage of time from the total duration of the considered six-month period when the temperature is in a given range. In Almaty, in just a year, the temperature in the refrigerator was in the required range $\left(0 \ldots+3{ }^{\circ} \mathrm{C}\right)$ for 31.1 days or 746.4 hours, which is $8.5 \%$ of the total duration of the year. In Kostanay, in just a year, the temperature in the refrigerator was in the required range $\left(0 \ldots+3{ }^{\circ} \mathrm{C}\right)$ for 103.0 days or 2471.4 hours, which is $28.2 \%$ of the total duration of the year. Those in Kostanay, the installation maintains the required temperature value three times longer than in Almaty. At the same time, air temperature below $0{ }^{\circ} \mathrm{C}$ is observed in Almaty $24.6 \%$, and in Kostanay $42.4 \%$ of the time of the total length of the year.

Let us compare the maximum temperature in a refrigerated volume per day with the average temperature of atmospheric air per day (see Fig. 9). The required 
temperature in the cooled volume is guaranteed to be maintained only if the average daily air temperature drops below $-13^{\circ} \mathrm{C}$. The minimum temperature in the cold accumulator (Fig. 10) per day was usually $5 \ldots 15 \mathrm{~K}$ higher than the minimum temperature of atmospheric air.

The power consumed by the P1 pump varies from 10 to $89 \mathrm{~W}$. The power consumed by the $\mathrm{P} 2$ pump is in the range of 45 to $103 \mathrm{~W}$. On average, the system consumes about $3.7 \mathrm{kWh}$ per day in Almaty and about $3.2 \mathrm{kWh}$ in Kostanay. The total electricity consumption by the installation for the period under review was $682.9 \mathrm{kWh}$ in Almaty and $601.3 \mathrm{kWh}$ in Kostanay. Of these, the circulation pump $\mathrm{P} 1$, supplying coolant to the radiators, consumed $55.4 \mathrm{kWh}$ in Almaty and $97.7 \mathrm{kWh}$ in Kostanay; P2 circulation pump supplying coolant to the air cooler- $222.4 \mathrm{kWh}$ in Almaty and $199.6 \mathrm{~kW}$ in Kostanay; the air cooler fan is $405.1 \mathrm{kWh}$ in Almaty and $304.1 \mathrm{kWh}$ in Kostanay.

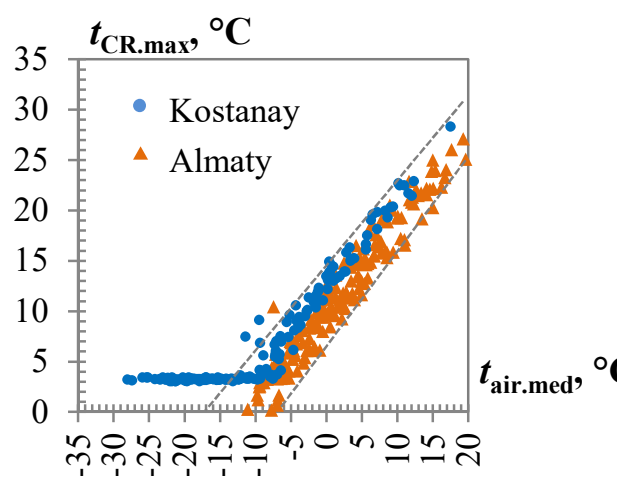

Figure 9. The dependence of the maximum daily temperature in the refrigerator compartment on the average daily temperature

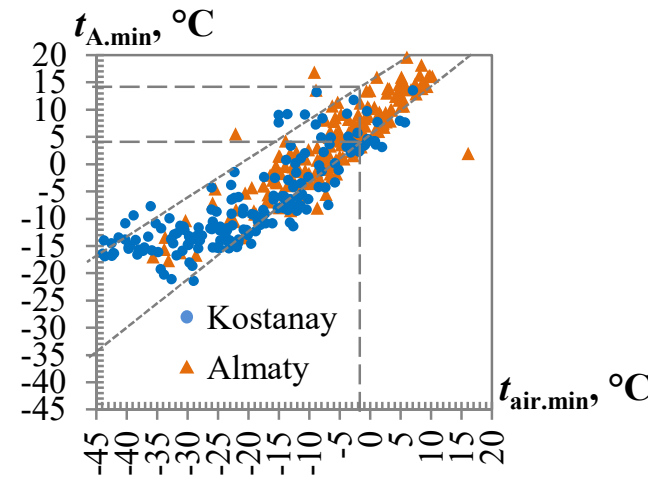

Figure 10. The dependence of the minimum daily temperature in the cold accumulator on the minimum daily air temperature

The specific heat output discharged from $1 \mathrm{~m}^{2}$ of the radiating surface of the radiator did not have pronounced seasonal patterns of change and ranged from 50 to $300 \mathrm{~W} / \mathrm{m}^{2}$ in Almaty (and up to $450 \mathrm{~W} / \mathrm{m}^{2}$ in Kostanay). The average annual value of the specific heat output discharged by radiators was $89.8 \mathrm{~W} / \mathrm{m}^{2}$ in Almaty and $115.3 \mathrm{~W} / \mathrm{m}^{2}$ in Kostanay.

The average value of the unit coefficient of performance over the period under consideration, defined as the ratio of the total amount of heat taken by the air cooler to the total amount of electricity consumed, is 3.43 in Almaty and 4.63 in Kostanay.

\section{CONCLUSION}

Computer simulation results show that in the climate of Almaty city, the application of the proposed installation using radiation cooling cannot be effective, since the required temperature $\left(0 \ldots+3{ }^{\circ} \mathrm{C}\right)$ is provided only $8.5 \%$ of the time of the 
total length of the year. In the city of Kostanay, the required temperature can be maintained for a much longer period of time (about $28.2 \%$ of the total length of the year). Although the result indicates that the proposed system can potentially operate, its application with the presented characteristics for solving practical problems is currently not advisable.

In further studies, it is planned to consider the possibility of using a combined refrigeration system, consisting of a unit with radiation cooling and a vapor compression refrigeration machine, and also to pay attention to studying the possibilities of reducing the energy consumption of air cooler fans. For example, instead of traditional air coolers, use cooling batteries.

\section{ACKNOWLEDGEMENTS}

This work was prepared under the project 0118PK00535, implemented on the basis of grant AP05130918, allocated under the program of the Ministry of Education and Science of the Republic of Kazakhstan for scientific and (or) scientific and technical projects for 2018-2020.

\section{NOMENCLATURE}

\begin{tabular}{|c|c|c|c|}
\hline$F$ & surface area, $\mathrm{m}^{2}$ & G & mass flow rate, $\mathrm{kg} / \mathrm{s}$ \\
\hline$N$ & total cloud cover, $\%$ & $P$ & power consumption, W \\
\hline$t$ & temperature, ${ }^{\circ} \mathrm{C}$ & $t_{\mathrm{CR}}$ & temperature in the refrigerator, ${ }^{\circ} \mathrm{C}$ \\
\hline$t_{\text {air.min }}$ & $\begin{array}{l}\text { minimum daily temperature } \\
\text { of the air, }{ }^{\circ} \mathrm{C}\end{array}$ & $t_{\mathrm{CR} \text {.max }}$ & $\begin{array}{l}\text { maximum daily air temperature } \\
\text { in the refrigerator, }{ }^{\circ} \mathrm{C}\end{array}$ \\
\hline$t$ air.med & $\begin{array}{l}\text { average daily temperature of } \\
\text { the air, }{ }^{\circ} \mathrm{C}\end{array}$ & $t_{\text {A.min }}$ & $\begin{array}{l}\text { minimum daily temperature } \\
\text { inside the cold accumulator, }{ }^{\circ} \mathrm{C}\end{array}$ \\
\hline$v$ air.med & $\begin{array}{l}\text { daily average wind speed, } \\
\mathrm{m} / \mathrm{s}\end{array}$ & & current time \\
\hline$\tau_{\mathrm{opt}}$ & $\begin{array}{l}\text { part of the day when the air } \\
\text { temperature inside the } \\
\text { refrigerator was in the } \\
\text { required range }\end{array}$ & & \\
\hline
\end{tabular}

\section{REFERENCES}

1. M.I. Ahmad, H. Jarimi, S. Riffat,2019. Nocturnal cooling technology for building applications. Springer. Singapore, $77 \mathrm{p}$. https://doi.org/https://doi.org/10.1007/978-981-13-5835-7.

2. A. Aili, D. Zhao, J. Lu, Y. Zhai, X. Yin, G. Tan, R. Yang, , 2019. A KWscale, 24-hour continuously operational, radiative sky cooling system: experimental demonstration and predictive modelling. Energy Conversion and Management. 186, 586-596. https://doi.org/10.1016/j.enconman.2019.03.006.

3. Bell, I.H., Wronski, J., Quoilin, S., Lemort, V., 2014. Pure and pseudo-pure fluid thermophysical property evaluation and the open-source thermophysical property library CoolProp. Industrial and Engineering Chemistry Research. 53(6), 2498-2508. https://doi.org/10.1021/ie4033999. 
4. B.O. Bolaji, Z. Huan, , 2013. Ozone depletion and global warming: case for the use of natural refrigerant - A review. Renewable and sustainable energy reviews. 18, 49-54. https://doi.org/10.1016/j.rser.2012.10.008.

5. Md.M. Hossain, M. Gu, , 2016. Radiative cooling: principles, progress, and potentials. Advanced Science. 1500360. https://doi.org/10.1002/advs.201500360.

6. G.D. Joubert, R.T. Dobson, 2017. Modelling and testing a passive night-sky radiation system. Journal of Energy in Southern Africa. 28(1), 76-90. https://doi.org/10.17159/2413-3051/2017/v28i1a1550.

7. V.I. Karagusov, R.Yu. Goshlya, V.S. Serdyuk, .S. Kolpakov, , V.A.Nemykin, V.I. Pogulyaev, 2018. Experimental stand for investigation of the radiation life - support systems: first experiments. AIP Conference Proceedings. 2007, 030014. https://doi.org/https://doi.org/10.1063/1.5051875.

8. V.I. Karagusov, V.S. Serdyuk, I.S. Kolpakov, V.A. Nemykin, V.I.Pogulyaev, 2018. Experimental determination of rate and direction of heat flow of the radiation life - support system with vacuum heat insulation. AIP Conference Proceedings. 2007, 030015. https://doi.org/https://doi.org/10.1063/1.5051876.

9. P. Karvounis, D. Koubogiannis, E. Hontzopoulos, A. Hatziapostolou, , 2019. Numerical and experimental study of flow characteristics in solar collector manifolds. Energies. 12(8). https://doi.org/10.3390/en12081431.

10. Zh. Liu, H. Tan, G. Ma, , 2017. Experimental investigation on night sky radiant cooling performance of duct-type heat exchanger. International Journal of Ventilation. 16(3), 255-267. https://doi.org/10.1080/14733315.2017.1299520.

11. D.G.L. Samuel, S.M.Sh. Nagendra, M.P. Maiya 2013. Passive alternatives to mechanical air conditioning of building: A Review. Building and Environment. 66, 54-64. https://doi.org/10.1016/j.buildenv.2013.04.016.

12. S. Tassou, Y. Ge, , 2008. Reduction of refrigeration energy consumption and environmental impacts in food retailing. Handbook of water and energy management in food processing. Woodhead Publishing Limited, 585-611. https://doi.org/10.1533/9781845694678.4.585.

13. J.a.F. Tevar, S. Castaño, Marijuán, a.G., Heras, M.R., Pistono, J., 2015. Modelling and experimental analysis of three radioconvective panels for night cooling. Energy and Buildings. 107, 37-48. https://doi.org/10.1016/j.enbuild.2015.07.027.

14. A.P. Tsoy, A.S. Granovskiy, A.V. Baranenko, D.A. Tsoy, , 2017. Effectiveness of a night radiative cooling system in different geographical latitudes. AIP Conference Proceedings. 1876, 020060. https://doi.org/https://doi.org/10.1063/1.4998880.

15. S. Vall, A. Castell, , 2017. Radiative cooling as low-grade energy source: a literature review. 77, 803-820. https://doi.org/10.1016/j.rser.2017.04.010.

16. Sh. Zhang, J. Niu, , 2012. Cooling performance of nocturnal radiative cooling combined with microencapsulated phase change material (MPCM) slurry storage. Energy and Buildings. 54, 122-130. https://doi.org/10.1016/j.enbuild.2012.07.041.

17. D. Zhao, A. Aili, Y. Zhai, J. Lu, D. Kidd, G. Tan, X. Yin, , R. Yang, , 2019. Subambient cooling of water: toward real-world applications of daytime radiative cooling. Joule. 3(1), 111-123. https://doi.org/10.1016/j.joule.2018.10.006. 
18. D. Zhao, A. Aili, Y. Zhai, Sh Xu, G. Tan, X. Yin, R. Yang, , 2019. Radiative sky cooling: fundamental principles, materials, and applications. Applied Physics Reviews. 6(2), 021306. https://doi.org/10.1063/1.5087281.

19. Riliable prognosis Rp5, 2019. World weather data archive. Accessed October 25, 2019. https://rp5.ru.

20. A.P. Tsoy, A.S. Granovskij, A.V. Baranenko, D.A. Tsoy, , 2015. Vliyanie klimata na rabotu holodilnoj sistemy, ispolzuyushej effektivnoe izluchenie $\mathrm{v}$ kosmicheskoe prostranstvo. Holodilnaya tehnika. 1, 43-46. (in Russian)

21. A.P. Tsoy, A.S. Granovskij, D.A. Tsoy, A.V. Baranenko, , 2019. Modelirovanie raboty ustanovki s radiacionnym ohlazhdeniem dlya kondicionirovaniya vozduha. Vestnik mezhdunarodnoj akademii holoda. 3, 314. https://doi.org/10.17586/1606-4313-2019-18-3-3-14. (in Russian) 